\title{
News Items
}

\section{Medical Audit-3}

The medical staff of the North Staffordshire Hospital centre at Stoke-on-Trent meet once a month $(5.00-6.00 \mathrm{pm})$ to discuss the management and treatment of a patient who has died the previous month. The staff includes 11 general physicians, two cardiologists, three neurologists, four paediatricians and two geriatricians. Each acts as chairman in turn and selects a suitable case from the deaths. The consultant for that case, or sometimes one of his juniors, then presents the case for comment by the assembled staff. Some initially were anxious, anticipating unwarranted criticism, but all are now enthusiastic about the educative value. Under the stimulus of example and discussion higher standards of patient care may be achieved. (W. Van't Hoff, 1981, Journal of the Royal College of Physicians of London, 15, 63.)

Note: The proper reference for 'Medical Audit-2' is C. L. Kaufmann and L. H. Roth (1981), 'Psychological evaluation of patient decision-making: Informed consent to ECT', Social Psychiatry, 16, 11-20.

\section{Audio-Visual Aids in Psychiatry}

Following the article which appeared in the Bulletin (February, 1981, p. 28), we have received further information about the availability of audio-visual teaching aids in psychiatry.

The Psychiatric Rehabilitation Association has produced several tape/slide programmes on various aspects of community care covering groupwork in a psychiatric setting; the day centre; residential care of the mentally ill; and industrial work for psychiatric patients. Enquiries should be addressed to PRA, The Groupwork Centre, 21a Kingsland High Street, London E8 2JS.

Some new publications which may be of interest to psychiatrists are now available from Camera Talks. A range of programmes under the heading of 'Mental Health' and covering about thirty separate topics can be had as a slideset or filmstrip. A new publication, 'Educating Mentally Handicapped People', has just been completed. Enquiries should be addressed to Camera Talks Ltd, 31 North Row (Park Lane), London W1R 2EN.

\section{Social Anthropology in Medical Education}

A joint meeting was held in Edinburgh on 15 November 1980 between the Edinburgh Transcultural Psychiatry Society and the British Medical Anthropology Society on the place of social anthropology in medical education. Forty participants attended from varying parts of the United Kingdom, and included social anthropologists, linguists, sociologists as well as psychiatrists. The following papers were presented:

The Nottingham Behavioural Sciences Course-Professor J. E. Cooper

Folk models of illness in an English Suburban community-Dr Cecil G. Helman

Insularity of psychiatry-Professor H. J. Walton

Social anthropology in the training of community physicians- $\mathrm{Dr}$ Jane Jackson

Concepts of illness among one Scottish group-Dr Carol MacCormack

The discussion, which readily crossed professional boundaries, was generated by a shared concern that medical anthropology should make an important contribution to the training of doctors. The importance of the conference was recognized by the British Medical .'ournal in a leading article published in December 1980.

\section{'Formattve Years'}

The Society for Mentally and Emotionally Handicapped Children at Mayo Hospital in Lahore have now published their first bulletin of child mental health, 'Formative Years'. Any articles dealing with basic knowledge of child development in underdeveloped countries, and more specifically the problems which face Pakistan, would be most welcome. Such contributions should be sent to the Editors (Drs Laeeq Mirza and Khalida Tareen), The Society for Mentally and Emotionally Handicapped Children, Child and Family Psychiatry Unit, Department of Paediatrics, Mayo Hospital, Lahore, Pakistan. 